\title{
GESTÃO SISTÊMICA DE ENERGIA E SUA CONTRIBUIÇÃO PARA A REDUÇÃO DOS GASES DE EFEITO ESTUFA - ABORDAGEM INTEGRADA DAS NORMAS ISO 50001:2011 E ISO 14064:2007
}

\author{
Nicole Celupi ${ }^{1 *}$, Ana Paula Dalla Corte ${ }^{2}$ \\ ${ }^{1 *}$ Three Phase Sustentabilidade e Gestão Empresarial, Curitiba, Paraná, Brasil, nicole@3phase-sustentabilidade.com.br \\ ${ }^{2}$ Universidade Federal do Paraná, Departamento de Ciências Florestais, Curitiba, Paraná, Brasil, anapaulacorte@gmail.com
}

\section{Resumo}

A crescente demanda por soluções sustentáveis para conter as mudanças climáticas tem exercido forte pressão sobre os setores públicos e privados. A norma ISO 50001, lançada em 2011, é uma das mais aguardadas nos últimos tempos, pois tem o propósito de habilitar organizações a estabelecerem sistemas e processos para a melhoria do desempenho energético, que consiste em eficiência energética, uso e consumo de energia. Se for amplamente aplicada pelos setores econômicos nacionais, estima-se que a norma possa influenciar até $60 \%$ do uso de energia do mundo, levando, consequentemente, à redução do custo de energia, das emissões de gases de efeito estufa e de outros impactos ambientais. Para demonstrar que a ISO 50001:2011 é uma importante ferramenta para as organizações com interesse na gestão ambiental e de energia, este trabalho tem como resultado a apresentação de um modelo de sistema de gestão de energia integrado à ISO 14064:2007. A metodologia empregada foi baseada num estudo de caso no qual se elaborou o diagnóstico inicial do sistema de gestão de energia de uma organização e o inventário das emissões de gases de efeito estufa de acordo com os requisitos normativos. Foram propostas oportunidades de melhoria à organização em estudo que servem não somente para melhorar seu desempenho energético, como também para reduzir as emissões de gases de efeito estufa.

Palavras-chave: Mudanças climáticas; Sistema de gestão; Desempenho energético; Inventário de gases de efeito estufa.

\begin{abstract}
Systemic management of energy and its contribution for the reduction of greenhouse gases integrated approach of ISO 50001:2011 and ISO 14064:2007 standards. The increasing demand for sustainable solutions to contain the climate changes has exerted strong pressure over the public and private sectors. The ISO 50001, published in 2011, is one of the most expected standards in the last years, since it has the main goal to qualify organizations to establish systems and processes to obtain better energetic performance, regarding energetic efficiency, use and energy consumption. If it is widely applied by the national economic sectors, it will be estimated that this standard could to influence $60 \%$ of the world energy use, leading to the energy cost reduction, greenhouse gases emissions and other environmental impacts. In order to demonstrate that ISO 50001:2011 is an important instrument to organizations with interests on environmental and energy management, this coursework had as result the presentation of an energy management system model integrated to ISO 14064:2007 - Greenhouse Gases. The methodology employed was based on a case study on which it was elaborated an initial diagnosis of the organization's energy management system and the greenhouse gas inventory in accordance with the standards requirements. Improvement opportunities were proposed to the organization which ones do not serve only to improve the energetic performance, but also to reduce the GHG emissions.
\end{abstract}

Keywords: Climate changes; Management system; Energetic performance; Greenhouse gases inventory.

\section{INTRODUÇÃO}

Desde metade do século passado, a energia é um tema estratégico da comunidade internacional dentro do conceito de desenvolvimento sustentável, uso eficiente dos recursos naturais e preservação ambiental. Poucas questões são mais estratégicas do que a energia. Apesar de todos os recentes desenvolvimentos e das novas políticas, o mundo não consegue ainda colocar o sistema 
global de energia numa trajetória mais sustentável. No cenário central de Novas Políticas projetado no World Energy Outlook, a procura mundial de energia crescerá mais de um terço até 2035, no qual a China, a Índia e o Médio Oriente representam 60\% desse aumento (IEA, 2012).

O setor de transportes responde pelo maior volume consumido de derivados de petróleo $(60,5 \%$ do total em 2006), enquanto a indústria demanda a maior parte da produção de carvão $(78,8 \%)$. Já o gás natural é utilizado principalmente por residências, agricultura, comércio e serviço público, que em 2006, juntos responderam por $48,1 \%$ do consumo mundial total, diante de um consumo industrial de $35,2 \%$. O conjunto desses setores também respondeu pela absorção do maior volume de energia elétrica no período $(56,7 \%)$, imediatamente seguido pela indústria $(41,6 \%)$. Quando considerado o volume total de energia fornecido, qualquer que seja a fonte, o grupo formado por residências, agricultura, comércio e serviço público se constitui no maior consumidor, responsável pela absorção de 2.937 milhões de tep (toneladas equivalentes de petróleo) em 2006. Na sequência vêm transportes, com 2.226 milhões de tep, e indústria, com 2.180 milhões de tep (ANEEL, 2008).

Não é novidade que a energia é fundamental para as operações das organizações e pode ter um custo significativo, independentemente de suas atividades. Para se ter uma ideia do que estes números representam, basta considerar o uso de energia pela cadeia de fornecimento de um negócio, desde a matéria prima até a reciclagem. Além dos custos econômicos para uma organização, a energia pode impor custos ambientais e sociais exaurindo recursos e contribuindo com problemas como a alteração climática. Nos cenários de políticas climáticas, de 2005 a 2030 a redução das emissões de $\mathrm{CO}_{2}$ relacionadas à energia pode ser conquistada em $54 \%$ no âmbito da eficiência energética e $23 \%$ por energias renováveis e bicombustíveis, é o que aponta o estudo do IEA (2008).

Segundo ANEEL (2008), a expansão acentuada do consumo de energia, embora possa refletir o aquecimento econômico e a melhoria da qualidade de vida, tem aspectos negativos. Um deles é a possibilidade do esgotamento dos recursos utilizados para a produção de energia. Outro é o impacto ao meio ambiente produzido por essa atividade. Finalmente, um terceiro são os elevados investimentos exigidos na pesquisa de novas fontes e construção de novas usinas.

Durante a Conferência das Nações Unidas sobre Mudanças Climáticas realizada em Copenhague em 2009, a COP 15, o Brasil assumiu a posição de vanguarda entre os países em desenvolvimento ao apresentar metas ambiciosas de redução de suas emissões de gases de efeito estufa (GEE). A meta voluntária brasileira foi de reduzir a emissão de GEE entre $36,1 \%$ a 38,9\% até 2020 (em relação ao que emitia em 1990) e foi oficializada pela Lei $n^{\circ} 12.187$ de 29 de dezembro de 2009 conhecida como Política Nacional sobre Mudança do Clima (PNMC). Segundo o Decreto n 7.390 de 09 de dezembro de 2010, que regulamenta a PNMC, a linha de base de emissões de gases de efeito estufa para 2020 foi estimada em $3,236 \mathrm{GtCO}_{2}$ eq. Assim, a redução absoluta correspondente ficou estabelecida entre 1,168 $\mathrm{GtCO}_{2}$ eq e 1,259 $\mathrm{GtCO}_{2}$ eq, 36,1\% e 38,9\% de redução de emissões, respectivamente.

Em sintonia com as preocupações mundiais, o Subcomitê de Mudanças Climáticas (SC-09) da ABNT/CB-38 - Gestão Ambiental colocou à disposição da sociedade em 2007 uma norma sobre os gases de efeito estufa, oferecendo orientações a todas as organizações interessadas em contribuir para a minimização do aquecimento global e as consequentes mudanças climáticas. Trata-se da ABNT NBR ISO 14064 - Gases de Efeito Estufa (ANBT, 2007). O Brasil esteve entre os setenta países que participaram do desenvolvimento deste documento, manifestando dessa forma sua preocupação com os efeitos resultantes daquele tema que vêm abalando várias regiões do planeta, não apenas aquelas intensamente industrializadas.

O mercado de créditos de carbono ainda não tem sido uma alternativa economicamente viável para conter as mudanças climáticas, portanto a norma da ISO oferece uma contribuição positiva facilitando os negócios, difundindo conhecimento, disseminando avanços tecnológicos inovadores e compartilhando boas práticas de gestão e avaliação da conformidade. De qualquer forma, o usuário da norma pode ainda obter vários benefícios, entre eles, a elaboração de Projetos de Mecanismo de Desenvolvimento Limpo (MDL), criado pelo Protocolo de Kyoto para regular o mercado de gases de efeito estufa, possibilitando que o País tenha oportunidades de compra e venda de Certificados de Emissões Reduzidas (ABNT, 2011).

Dentro das questões apresentadas sobre energia e mudanças climáticas, é necessário o desenvolvimento e a implementação de tecnologias para as novas fontes energéticas e fontes de energia renováveis, entretanto podem levar tempo. As organizações não podem controlar os preços de energia, as políticas governamentais ou a economia mundial, mas elas podem melhorar o modo como gerenciam a energia neste momento. A melhoria do desempenho energético pode proporcionar benefícios imediatos para uma organização pela maximização do uso de suas fontes de energia e dos 
bens relacionados a ela, reduzindo assim tanto o custo como o consumo. A organização contribuirá de modo positivo para a redução do esgotamento de recursos energéticos e mitigação dos efeitos mundiais do uso de energia, como o aquecimento global.

Existe outra norma que vem atraindo bastante atenção da sociedade: é a NBR ISO 50001 (ABNT, 2011) Sistemas de gestão da energia - Requisitos com orientações de uso. A norma tem como propósito habilitar organizações a estabelecerem sistemas e processos necessários para melhorar o desempenho energético, incluindo eficiência energética, uso e consumo de energia. Sua implementação visa levar a reduções das emissões de GEE e outros impactos ambientais associados e do custo de energia, por meio de uma gestão sistemática da energia.

A ISO 50001 (ABNT, 2011) está baseada no modelo de sistema de gestão que já é compreendido e implementado por organizações ao redor do mundo. Ela pode fazer uma diferença positiva para as organizações de todos os tipos em um futuro muito próximo, influenciando em $60 \%$ do uso da energia mundial e apoiando esforços de longo prazo para o aprimoramento de tecnologias de energia (ABNT, 2012). Para atingir este objetivo, é necessário que as empresas conheçam seus benefícios e suas implicações, assim como os da ISO 14064 (ANBT, 2007), pois nem todas as organizações se sentem impulsionadas a prover recursos e encarar os desafios da implantação de um SGE ou da elaboração do inventário de GEE. As duas normas aliadas podem ser ferramentas poderosas contribuindo positivamente e simultaneamente para as mudanças climáticas e para aumentar o desempenho da gestão de energia nas empresas.

Portanto, este trabalho pretende demonstrar como a aplicação conjunta da ISO 50001 (ABNT, 2011) e da ISO 14064 (ANBT, 2007) pode contribuir para aumentar o desempenho da gestão de energia nas empresas e minimizar seus impactos oriundos de suas atividades, produtos ou serviços nas mudanças climáticas. Desta forma, pretende-se realizar um diagnóstico inicial do sistema de gestão de energia de uma organização, quantificar os gases de efeito estufa e propor um modelo de SGE segundo a ISO 50001 (ABNT, 2011) de forma que as oportunidades de melhoria definidas neste modelo sirvam também para reduzir as emissões de GEE.

\section{MATERIAL E MÉTODOS}

Para a execução do trabalho foram utilizados os conceitos e as metodologias definidas pelas normas ABNT NBR ISO 50.001 e ABNT NBR ISO 14064. Neste tópico encontram-se explicações sobre os materiais e métodos empregados para o atendimento aos requisitos normativos aplicáveis a este trabalho. Portanto, não foram aplicados todos os requisitos normativos, visto que se trata de um diagnóstico inicial do SGE de uma organização e como melhorias no desempenho deste sistema podem contribuir para a redução das emissões de GEE. Os requisitos normativos atendidos são os que aparecem na Figura 1.

Inicialmente, apresentam-se de forma concisa as etapas compreendidas para o atendimento aos requisitos da norma ISO 50001 aplicáveis, contendo informações das técnicas e teorias utilizadas. $\mathrm{Na}$ sequência, o mesmo é descrito para a norma ISO 14064. Para obter resultados práticos, escolheuse uma empresa como objeto de estudo do ramo de fabricação de equipamentos para a geração de energia.

A definição do escopo e as fronteiras do sistema de gestão de energia da organização em estudo, o estabelecimento dos limites organizacionais e operacionais e o ano-base do inventário de GEE foram os primeiros passos para o desenvolvimento do estudo. O escopo e as fronteiras do SGE (Sistema de Gestão de Energia) foram definidos pelos responsáveis da organização objeto de estudo devido à necessidade de fornecerem informações, assim como interesse técnico envolvido. Foi utilizada a abordagem da consolidação baseada no controle operacional para estabelecer os limites organizacionais do inventário de GEE, na qual a organização responde por $100 \%$ das emissões de GEE de operações sobre as quais tem controle (financeiro ou operacional). Tais operações caracterizaram os limites operacionais do inventário de GEE. O estabelecimento do ano-base constituiu-se de um período no qual a organização possuía informações históricas a serem fornecidas. 


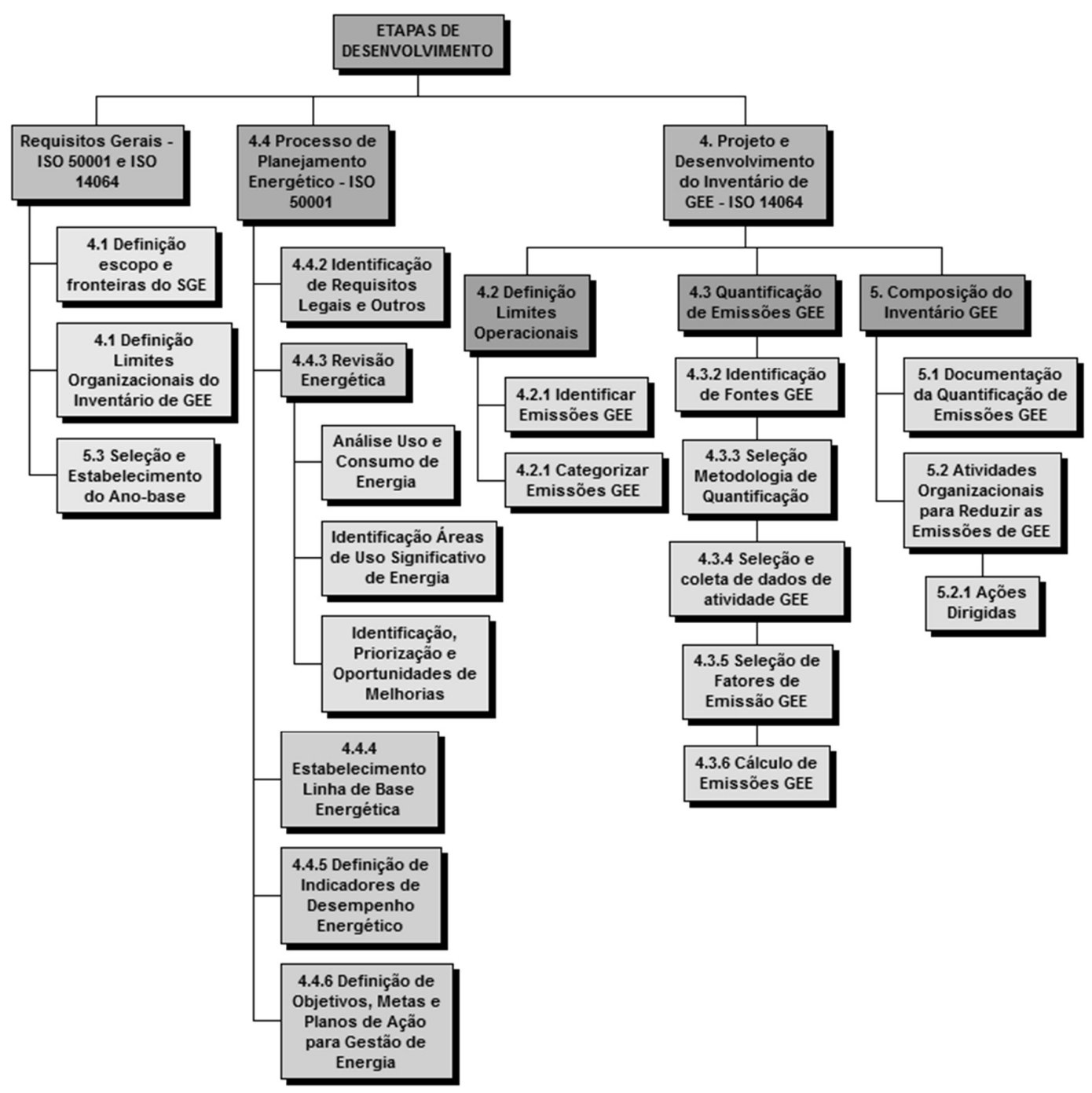

Figura 1. Etapas de desenvolvimento do trabalho.

Visando obter foco no desempenho energético da organização e nas ferramentas para manter e melhorar continuamente este desempenho, foi definido um processo de planejamento energético. Dentro deste processo, foram realizadas as seguintes atividades: identificação dos requisitos legais e outros, desenvolvimento da revisão energética, estabelecimento da linha de base, identificação de indicadores de desempenho energético e o estabelecimento de objetivos, metas e planos de ação para gestão de energia. Cada uma destas etapas está explicada nos parágrafos seguintes.

É indispensável que toda a organização cumpra com os requisitos legais aplicáveis a suas atividades, produtos e serviços. Então, a identificação dos requisitos legais no âmbito do consumo e uso de energia foi necessária não somente para atender à ISO 50001 como também aos órgãos reguladores. Para isso, foram consultados os sites da Agência Nacional de Energia Elétrica - ANEEL e Ministério de Minas e Energia - MME.

Dentro da revisão energética foram identificados e avaliados o uso e consumo atual de energia com base em dados práticos, técnicos ou nominais das instalações, equipamentos, sistemas e processos. Foram objetos de estudo as contas de energia elétrica, variáveis produtivas (quantidade e tempo), manuais e listas técnicas de equipamentos e máquinas, fontes de energia, observação das pessoas trabalhando, condições físicas das instalações, equipamentos e máquinas, procedimentos e controles operacionais. Grande parte destas informações foi fornecida pelos responsáveis pelo sistema de gestão da qualidade e ambiental da organização em estudo, outras foram coletadas em visitas de campo e através de pesquisas na literatura existente. A partir desse levantamento pode-se avaliar e 
determinar as áreas que afetam significativamente o uso e consumo de energia para que se pudesse elaborar uma lista de recomendações priorizadas para melhoria em termos de desempenho energético.

Para a organização determinar o período de manutenção de registros foi necessário estabelecer uma linha de base energética. Para tanto, considerou-se uma variável crítica que é o ciclo de atividade do negócio. E para que a organização possa comparar com a linha de base energética e informar o desempenho energético de suas operações foram escolhidos indicadores de desempenho energético (IDE) adotando-se IDE's de simples parâmetro, simples razão e modelo complexo. A partir da revisão energética estabeleceram-se objetivos e metas nos processos e instalações relevantes da organização.

O diagnóstico inicial do SGE encerrou-se com a definição do plano de ação para o cumprimento dos objetivos e metas para a gestão de energia. A seguir, estão descritos os métodos utilizados para o projeto e desenvolvimento do inventário de GEE.

A ISO 14064 detalha os princípios e requisitos para planejar, desenvolver, gerenciar e relatar inventários de GEE em organizações ou empresas. Com o intuito de atingir o objetivo deste trabalho e dentro do tempo disponível para sua execução, optou-se por atender aos requisitos de planejamento e desenvolvimento do inventário de GEE, ficando a cargo da empresa objeto de estudo a decisão por dar continuidade ao gerenciamento e relato do mesmo.

Dentro dos limites organizacionais, a quantificação de emissões de GEE foi realizada em cinco sub-etapas. A primeira sub-etapa consistiu da identificação de fontes de GEE, o que basicamente já havia sido realizada na etapa de definição dos limites operacionais. Portanto, resumiu-se em documentar sistemicamente as fontes.

A segunda sub-etapa foi selecionar uma metodologia que minimizasse razoavelmente a incerteza e que gerasse resultados precisos, consistentes e reprodutíveis para a quantificação dos GEE. Sendo assim, optou-se pela ferramenta de contabilidade internacional do Protocolo GHG (2011) que permitiu compreender e quantificar os GEE, a qual é amplamente utilizada por governos e empresas de todo o mundo. O Protocolo GHG (2011) fornece um quadro contábil para a medição de quase todos os GEE padrões existentes e a conversão desses poluentes em $\mathrm{CO}_{2}$ equivalente, a equivalência é utilizada como parâmetro para inventários de emissões de GEE.

A seleção e coleta de dados fizeram parte da terceira sub-etapa. Quantidade de energia, combustíveis e eletricidade consumida, material produzido, serviço fornecido e área territorial afetada foram alguns dos dados coletados para serem consistentes com os requisitos da metodologia de quantificação do Protocolo GHG (2011). No entanto, esses dados somente puderam ser utilizados em combinação com fatores de emissão, os quais foram obtidos de uma origem reconhecida durante a quarta sub-etapa. Mais uma vez, foram selecionados os fatores de emissão do programa Protocolo GHG (2011) que basicamente utilizou como fonte o Intergovernmental Panel on Climate Change (IPCC, 2006).

De acordo com a metodologia de quantificação selecionada, calcularam-se as emissões de GEE multiplicando-se os dados de atividades pelos fatores de emissão, quando aplicável. Este cálculo fez parte da quinta sub-etapa da quantificação de emissões de GEE.

A última etapa do projeto e desenvolvimento do inventário de GEE compreendeu a documentação da etapa de quantificação de emissões e do planejamento das ações dirigidas para reduzir ou prevenir emissões ou aumentar as remoções de GEE.

\section{RESULTADOS E DISCUSSÃO}

\section{Requisitos gerais}

O escopo do sistema de gestão de energia em estudo compreende as atividades de fabricação de torres eólicas de aço em diversas alturas na configuração cônica, as quais suportam geradores eólicos de $900 \mathrm{~kW}$ a $4000 \mathrm{~kW}$. As atividades são as seguintes:

- Movimentação de materiais: atividade de descarregamento de matérias-primas e insumos do processo produtivo, movimentação de produtos semi-acabados e carregamento de produtos acabados;

- Corte: processo de transformação de chapas metálicas de aço em pedaços;

- Calandragem: processo de conformação pelo qual se dá forma a chapas e/ou laminados de metal, pela passagem entre rolos, conferindo-lhes assim curvatura, espessura constante e um acabamento de qualidade; 
- Soldagem a arco submerso: processo que visa a união localizada de materiais, similares ou não, de forma permanente, baseada na ação de forças em escala atômica semelhantes às existentes no interior do material e é a forma mais importante de união permanente de peças usadas industrialmente;

- Jateamento: processo mecânico onde a superfície tratada é submetida ao impacto de um jato de granalhas a alta velocidade, impelidas usando ar a alta pressão, que causam deformações plásticas resultando em tensões residuais de compressão na superfície da peça;

- Pintura: processo de aplicação de pigmento uma superfície a uma superfície, a fim de colori-la, atribuindo-lhe proteção, tons e texturas.

As fronteiras compreendem os limites físicos e organizacionais e se caracterizam pelo local da instalação aonde as atividades envolvidas na fabricação de torres eólicas descritas acima são realizadas. Para preservar a imagem da organização que forneceu as informações para a realização deste trabalho, não será divulgada sua identidade nem mesmo sua localização. Porém, é importante destacar que as atividades acima são realizadas dentro de um único galpão de produção.

Os limites organizacionais do inventário de GEE caracteriza-se pelas atividades e instalação descrita no item 3.1.1. Portanto, possui o mesmo escopo e fronteiras do sistema de gestão de energia. Os limites operacionais constituem-se das emissões de GEE associadas às operações da organização em estudo e estão apresentados no item 3.3.1 deste trabalho.

Não existem sumidouros de gases de efeito estufa dentro dos limites organizacionais e operacionais do inventário. O ano-base escolhido foi o do período de outubro de 2011 a setembro de 2012 devido à existência de dados verificáveis de emissões de GEE.

\section{Processo de planejamento energético}

Requisitos legais no âmbito nacional foram identificados como aplicáveis ao escopo do sistema de gestão de energia da organização em estudos e constam na Tabela 1. Não foram identificados outros requisitos como, por exemplo, acordos com clientes, princípios ou códigos de boas práticas voluntários ou programas voluntários.

Tabela 1. Requisitos legais aplicáveis para o estudo de caso

$$
\text { Requisito Legal }
$$

\section{Requisito Legal}

Decreto $n^{\circ} 87079 / 82$ - Programa de Mobilização
Energética;
Portaria Interministerial n 1877/85 - Procel;
Decreto n 99.656/90 - Administração Federal e Cice;
Decreto de 18/07/91- CONPET;
Decreto de 08/12/93 - Prêmio Nacional da Conservação
de Energia;
Lei nº 9427/96 - ANEEL;
Lei $n^{\circ} 9478 / 97$ - Lei do Petróleo e ANP;
Lei $n^{\circ}$ 9991/00 - Investimentos em pesquisa e
desenvolvimento e em eficiência energética;

Resolução no 456/00 - Condições Gerais de Fornecimento de Energia Elétrica.

Lei $n^{\circ} 9991 / 00$ regulamentada pelo decreto $n^{\circ} 3867 / 01$ Fundo Setorial de Energia; Decreto $n^{\circ} 4131 / 02$ - Medidas emergenciais de redução do consumo de energia elétrica;

Resolução n 492/02;

Lei $n^{\circ}$ 10438/02 - Proinfa e CDE;

Decreto $n^{\circ}$ 5267/04 - MME;

Lei $n^{\circ} 10848 / 04$ - Comercialização de energia elétrica;

Resolução Normativa $n^{\circ}$ 300/08 - Aplicação de recursos em programas de eficiência energética;

Lei $n^{\circ}$ 12212/10 - Tarifa Social de Energia Elétrica;

Instrução Normativa $\mathrm{n}^{\circ} \quad 01 / 10$ - Critérios de sustentabilidade ambiental na aquisição de bens, contratação de serviços ou obras;

Lei $\mathrm{n}^{\circ} 12.431 / 11$ - Imposto sobre a renda nas operações.

Lei $n^{\circ} 10295 / 01$ regulamentada pelo decreto $n^{\circ} 4059 / 01$

- Lei da Eficiência Energética;

A identificação da situação do desempenho energético da organização foi realizada visando entender onde a energia está sendo usada e formar a base de esforços para melhorias. Baseado nos dados coletados foi elaborado a Tabela 1, na qual podem ser observados os tipos, usos e consumos 
das energias utilizadas. Através desta tabela, verifica-se que a principal energia utilizada é a eletricidade e que o transporte interno e soldagem são os usos que demandam maior variedade de energia, podendo ser as áreas onde poderá ser empregado um maior número de oportunidades de melhorias.

Ainda na Tabela 2 encontra-se a classificação das energias em relação à economia da organização, impacto na produção e requisitos legais e outros. Os critérios adotados para classificar as energias estão apresentados no Tabela 3. O índice de significância foi obtido somando-se a pontuação de cada critério de classificação.

Tabela 2. Usos e consumos de energia

\begin{tabular}{|c|c|c|c|c|c|c|}
\hline \multirow{3}{*}{\multicolumn{2}{|c|}{ Energia }} & \multirow{3}{*}{ Eletricidade } & \multicolumn{4}{|c|}{ Combustíveis } \\
\hline & & & \multicolumn{3}{|c|}{ Fóssil } & \multirow{2}{*}{$\begin{array}{c}\text { Não fóssil } \\
\text { Gás mistura } \\
\text { C25 }\end{array}$} \\
\hline & & & GLP & Acetileno & Óleo diesel & \\
\hline & Ventilação & $\bar{X}$ & & \multirow{7}{*}{$x$} & \multirow{7}{*}{$x$} & \multirow{7}{*}{$x$} \\
\hline & Iluminação & $x$ & & & & \\
\hline & Transporte Interno & $x$ & $\mathrm{x}$ & & & \\
\hline & Soldagem & $\mathrm{X}$ & & & & \\
\hline & Jateamento & $x$ & & & & \\
\hline & Pintura & $\mathrm{X}$ & & & & \\
\hline & Linhas produtivas & $\hat{x}$ & & & & \\
\hline & Consumo de Energia & $\begin{array}{c}144.907 \mathrm{kWh} / \\
\text { mês }\end{array}$ & 450 kg/ mês & 450 kg/ mês & 150 I/ mês & $50 \mathrm{Kg} /$ mês \\
\hline \multirow{4}{*}{$\begin{array}{l}0 \\
\mathbb{D} \\
\mathscr{D} \\
\mathbb{\sigma} \\
U\end{array}$} & Econômico & 2 & 1 & 1 & 1 & 1 \\
\hline & Impacto na Produção & 3 & 2 & 3 & 2 & 3 \\
\hline & Requisitos Legais & 3 & 3 & 3 & 3 & 3 \\
\hline & Índice de Significância & 8 & 6 & 7 & 6 & 7 \\
\hline
\end{tabular}

Estabeleceu-se que os índices maiores ou iguais a cinco representam as áreas de uso significativo e a organização deve proceder conforme apresentado a seguir:

- $<5$ Uso não significativo: A organização deve manter controles operacionais relacionados ao uso e consumo de energia.

- $\geq 5$ Uso significativo: A organização deve adotar ações de melhoria relacionadas ao uso e consumo de energia de forma a diminuir sua significância.

Tabela 3. Critérios de determinação da significância

\begin{tabular}{|c|c|c|}
\hline \multirow{4}{*}{ Econômico } & Ponto & Critério \\
\hline & 1 & $\begin{array}{c}\text { Baixo: O custo com energia representa menos de } 5 \% \text { do lucro bruto da } \\
\text { organização. }\end{array}$ \\
\hline & 2 & Médio: O custo com energia representa de $5 \%$ a $10 \%$ do lucro bruto da organização. \\
\hline & 3 & Alto: O custo com energia representa mais de $10 \%$ do lucro bruto da organização. \\
\hline \multirow{3}{*}{$\begin{array}{l}\text { Impacto na } \\
\text { produção }\end{array}$} & 1 & Baixo: A qualidade da energia empregada não pode causar efeitos na produção. \\
\hline & 2 & $\begin{array}{l}\text { Médio: A qualidade da energia empregada pode causar efeitos na produção como perda } \\
\text { de energia, perda de tempo ou queima de equipamento sem ocorrer parada } \\
\text { significativa da produção. }\end{array}$ \\
\hline & 3 & Alto: A qualidade da energia empregada pode causar parada significativa da produção. \\
\hline \multirow{3}{*}{$\begin{array}{l}\text { Requisitos } \\
\text { legais }\end{array}$} & 1 & $\begin{array}{l}\text { Baixo: Não existem requisitos legais ou outros relacionados ao uso ou consumo de } \\
\text { energia. }\end{array}$ \\
\hline & 2 & Médio: Existem outros requisitos relacionados ao uso ou consumo de energia. \\
\hline & 3 & Alto: Existem requisitos legais relacionados ao uso ou consumo de energia. \\
\hline
\end{tabular}

Diversas são as oportunidades identificadas visando à melhoria do desempenho energético. $\mathrm{O}$ 
item 3.2.5 traz em detalhes a proposta contendo as ações direcionadas ao atendimento dos objetivos energéticos. A linha de base é o ponto de partida para as melhorias, a linha a partir da qual todas as mudanças no desempenho da energia deverão ser medidas. Com base nas informações da revisão energética, consideraram-se os dados do período compreendido entre outubro de 2011 e setembro de 2012 para estabelecer a linha de base energética.

No entanto, a linha de base determinada não é a ideal, pois deveria considerar todos os tipos de energia utilizados. Para que isto pudesse ter sido atendido, a organização em estudo deveria possuir medidores automáticos de consumo de energia elétrica instalados em pontos estratégicos para que se pudessem obter medições específicas. Para outras fontes energéticas, a organização deveria utilizar dados registrados de leitura visual de consumo de combustíveis, geralmente semanais ou mensais, dependendo da quantidade usada. Devido a essas limitações, para este trabalho pode-se apenas adotar o consumo de energia elétrica de $144.907 \mathrm{kWh} /$ mês como linha de base, obtido a partir das contas do fornecedor de serviço público.

Para uma avaliação de desempenho, um indicador deve ser visto como uma medida quantitativa de algum aspecto particular do desempenho da organização. É um instrumento de apoio ao monitoramento da eficiência e da eficácia, simplificando uma avaliação que de outro modo seria mais complexa e subjetiva. Assim, os indicadores de desempenho devem, dentre outros requisitos, estarem claramente definidos, serem representativos dos aspectos que se busca avaliar e serem verificáveis (KUSTERKO, 2009). De forma a permitir uma avaliação de desempenho apropriada, o número de indicadores a utilizar deve ser cuidadosamente ponderado. Como referido, não tem significado e é por vezes enganador usar um único indicador para fazer um diagnóstico.

Para avaliação do desempenho energético em estudo, desenvolveram-se os seguintes indicadores como medidas mensuráveis:

- Custo unitário da energia elétrica adquirida da concessionária (R\$/MWh);

- Custo de energia consumida por peça produzida (R\$/ unidade);

- Valor faturado por peça vendida (R\$/ unidade);

- Quantidade de gás consumido por hora trabalhada $(\mathrm{kg} / \mathrm{h})$;

- Quantidade de óleo diesel consumido por hora trabalhada (L/ h);

- Quantidade de energia elétrica consumida por hora trabalhada (MWh)

- Índice de consumo de energia renovável;

- Quantidade de emissões de GEE ( $\left.\mathrm{tCO}_{2} \mathrm{eq}\right)$;

- Índice de atendimento às Normas de Segurança;

- Índice de fator de carga: é a razão entre a demanda média, durante um determinado intervalo de tempo, e a demanda máxima registrada no mesmo período, conforme definição dada pela Resolução ANEEL n 456/00;

- Índice de fator de potência: está relacionado à presença de energia reativa, indutiva ou capacitiva, causada por determinados dispositivos elétricos ou eletrônicos. Conforme definição dada pela Resolução ANEEL n 456/00: "é um índice que mostra a razão entre a energia elétrica ativa e a raiz quadrada da soma dos quadrados das energias elétricas ativas e reativas, consumidas num mesmo período especificado".

Acredita-se que os indicadores de desempenho energético (IDE) definidos acima são suficientes para destacar aspectos relevantes do sistema de gestão de energia, porém implicam em uma constante reavaliação e adequação conforme as necessidades.

A organização em estudo não possui uma política energética direcionada para a implementação de um SGE. No entanto, existe uma intenção não declarada para aumentar seu desempenho energético. Para que estas intenções se transformem em ações foram estabelecidos os objetivos apresentados na Tabela 4, tomando-se como base os resultados obtidos na revisão energética. Ao lado de cada objetivo estão relacionados os indicadores que servirão para informar à organização o seu desempenho energético.

Porém, o estabelecimento de objetivos não é o suficiente para se obter um processo de controle estratégico, deve ainda ocorrer uma comparação com padrões previamente definidos (metas). Uma das formas para se estabelecer metas seria coletar dados históricos obtidos pela organização referentes aos indicadores. Outra forma seria pesquisar na literatura valores obtidos por organizações similares. No entanto, o estabelecimento destes padrões (metas) emergiu como um problema, pois a organização objeto de estudo não possui dados históricos e não foi o foco deste trabalho fazer uma pesquisa literária buscando por tais padrões. Portanto, para não haver chance de as metas 
supostamente definidas não serem realistas nem desafiadoras, podendo levar à perda de credibilidade e à desmotivação em relação ao seu atendimento, não foram estabelecidas metas neste trabalho.

Tabela 4. Objetivos energéticos

\begin{tabular}{|c|c|c|c|c|}
\hline Energia & $\begin{array}{c}\text { Uso } \\
\text { significativo de } \\
\text { energia }\end{array}$ & Objetivos & IDE & Unidade \\
\hline Eletricidade & SIM & \multirow{3}{*}{$\begin{array}{c}\text { Garantir } \\
\text { sustentabilidade } \\
\text { econômico-financeira da } \\
\text { organização }\end{array}$} & $\begin{array}{l}\text { Custo unitário da energia elétrica } \\
\text { adquirida da concessionária }\end{array}$ & $\mathrm{R} \$ / \mathrm{MWh}$ \\
\hline $\begin{array}{l}\text { Eletricidade e } \\
\text { combustível }\end{array}$ & SIM & & $\begin{array}{l}\text { Custo de energia consumida por } \\
\text { peça produzida }\end{array}$ & $\mathrm{R} \$$ /unidade \\
\hline $\begin{array}{l}\text { Eletricidade e } \\
\text { combustível }\end{array}$ & SIM & & Valor faturado por peça vendida & $\mathrm{R} \$$ /unidade \\
\hline Eletricidade & SIM & \multirow{3}{*}{$\begin{array}{c}\text { Reduzir as } \\
\text { quantidades de energia } \\
\text { consumida }\end{array}$} & $\begin{array}{l}\text { Quantidade de energia elétrica } \\
\text { consumida por hora trabalhada }\end{array}$ & kWh \\
\hline Combustível & SIM & & $\begin{array}{l}\text { Quantidade de gás consumido } \\
\text { por hora trabalhada }\end{array}$ & $\mathrm{kg} / \mathrm{h}$ \\
\hline Combustível & SIM & & $\begin{array}{l}\text { Quantidade de óleo diesel } \\
\text { consumido por hora trabalhada }\end{array}$ & $\mathrm{L} / \mathrm{h}$ \\
\hline \multirow{2}{*}{$\begin{array}{l}\text { Eletricidade e } \\
\text { combustível }\end{array}$} & \multirow{2}{*}{ SIM } & \multirow{2}{*}{$\begin{array}{l}\text { Diminuir o potencial de } \\
\text { aquecimento global }\end{array}$} & $\begin{array}{l}\text { Índice de consumo de energia } \\
\text { renovável }\end{array}$ & - \\
\hline & & & Quantidade de emissões de GEE & $\mathrm{tCO}_{2} \mathrm{eq}$ \\
\hline $\begin{array}{l}\text { Eletricidade e } \\
\text { combustível }\end{array}$ & SIM & $\begin{array}{l}\text { Assegurar a produção } \\
\text { em condições normais }\end{array}$ & $\begin{array}{l}\text { Índice de atendimento às normas } \\
\text { de segurança }\end{array}$ & - \\
\hline Eletricidade & SIM & $\begin{array}{l}\text { Utilizar energia elétrica } \\
\text { de forma racional }\end{array}$ & Índice de fator de carga & - \\
\hline Eletricidade & SIM & $\begin{array}{l}\text { Aumentar a eficiência } \\
\text { energética de } \\
\text { equipamentos e } \\
\text { sistemas elétricos }\end{array}$ & Índice de fator de potência & - \\
\hline
\end{tabular}

De qualquer forma, algumas recomendações são importantes para que a organização possa definir suas metas futuramente:

- As metas devem declarar os níveis de desempenho minimamente aceitáveis e devem, preferencialmente, ser quantificáveis possibilitando durante sua execução, a identificação dos fatores críticos de sucesso, das ameaças e oportunidades e dos pontos fracos e fortes em relação aos resultados finais e intermediários esperados (SEBRAE, 2011);

- As metas devem ser escritas de forma que, mesmo pessoas não familiarizadas com a organização, sejam capazes, apenas pela leitura, de entender os resultados esperados (SEBRAE, 2011);

- Uma meta difícil de ser alcançada pode levar a um comprometimento exagerado de recursos;

- Se as metas definidas são muito difíceis de serem alcançada, os executivos são levados a tomar decisões de alcance a curto prazo que não se coadunam com os interesses a longo prazo da empresa (REIS; MORGAN, 2002);

- Metas exequíveis reduzem a tentação dos executivos de manipulação dos dados;

- Quando a organização consegue cumprir ou ultrapassar as suas metas, é criado um clima de atitudes positivas na empresa (REIS; MORGAN, 2002).

A seguir estão propostas as ações que contribuirão para que a organização atinja os objetivos energéticos anteriormente definidos. Para a definição de grande parte dessas ações tomou-se como base as recomendações descritas no Manual de Eficiência Energética na Indústria, elaborado pela COPEL (2005).

a) Análise das contas de energia pelas áreas técnicas da empresa. Para que essa análise resulte em redução efetiva de despesas, é importante um bom conhecimento da legislação que regulamenta o 
fornecimento de energia elétrica, a qual estabelece as modalidades tarifárias disponíveis, as grandezas a serem utilizadas para o faturamento, os parâmetros fixados em contrato, bem como regula o relacionamento concessionária - consumidor de eletricidade;

b) Instalação de equipamentos para medição do consumo de energia em diversos locais, como: seções, galpões, circuitos e máquinas;

c) Programação e controle da produção bem elaborada. Isto significa que automaticamente haverá economia de energia, pois as máquinas operatrizes e os sistemas de utilidade são mais bem aproveitados, os picos produtivos atenuados, etc. Por isso, a programação da produção deve ser aprimorada de tal maneira que: as máquinas e os equipamentos elétricos operem o mais próximo possível de sua capacidade nominal; sua produção seja, dentro das possibilidades, contínua; as operações que mais requeiram energia elétrica ocorram nos períodos de tarifas mais baixas, etc. $O$ consumo de eletricidade deve ser considerado como uma variável importante na elaboração de uma programação da produção;

d) Reavaliar as especificações técnicas de seus produtos e seus processos produtivos, com o intuito de verificar possibilidades da redução do consumo de energia para produzi-la;

e) Implantação de um controlador de demanda e o estabelecimento de uma programação de cargas elétricas. Controlar automaticamente a demanda de potência de uma indústria significa supervisionar, através de um sistema automático, as potências médias de 15 minutos solicitadas do sistema elétrico da concessionária, de tal forma que estas não ultrapassem um valor predeterminado como ótimo. Por programação de cargas elétricas entende-se um planejamento rígido de funcionamento das máquinas elétricas de uma indústria, procurando escalonar o seu funcionamento ao longo da jornada de trabalho e dos períodos horosazonais. A obtenção da curva de carga de um dia típico de operação da indústria contribui sobremaneira para uma boa programação de cargas;

f) Adotar métodos de correção do fator de potência. A correção do fator de potência deverá ser cuidadosamente analisada e não resolvida de forma simplista, já que isto pode levar a uma solução técnica e economicamente não satisfatória. É preciso critério e experiência para efetuar uma adequada correção, lembrando que cada caso deve ser estudado especificamente e que soluções imediatas podem não ser as mais convenientes. De modo geral, quando se pretende corrigir o fator de potência de uma instalação surge o problema preliminar de se determinar qual o melhor método a ser adotado. Independente deste método, o fator de potência ideal, tanto para os consumidores como para as concessionárias, seria o valor unitário $(1,0)$, que significa inexistência da energia reativa no circuito. Entretanto, esta condição nem sempre é conveniente e, geralmente, não se justifica economicamente. A correção efetuada até o valor de 0,95 é considerada suficiente. Os métodos mais utilizados na prática são: Alteração das condições operacionais ou substituição de equipamentos e Correção por capacitores estáticos;

g) Programa de uso de motores. Podem fazer parte deste programa:

- Escolha adequada de motores de indução: sob o ponto de vista da conservação de energia elétrica, o principal parâmetro a ser observado é a potência nominal do motor, que deve ser adequada para o serviço a que se destine. Potências nominais muito superiores à realmente necessária resultam em desperdícios de energia, elevação da potência solicitada, redução do fator de potência da instalação elétrica e maiores perdas nas redes de distribuição de energia e nos transformadores. Deve-se, sempre que possível, escolher o motor de modo que seu carregamento seja no mínimo superior a $50 \%$, dando preferência a que ele seja maior que $75 \%$;

- Implantação e o cumprimento de um programa ótimo de manutenção preventiva e corretiva de todos os motores elétricos e das máquinas por eles acionadas;

- Modernização de máquinas, resultando em menores necessidades de potência e, consequentemente, redução do consumo de energia elétrica;

- Controles de velocidade variável.

h) Programa de uso de transformadores. Podem fazer parte deste programa:

- Eliminação progressiva dos transformadores muito antigos, substituindo-os, quando ocorrerem 
avarias, por outros mais modernos;

- Manter os transformadores desligados quando não estiverem em serviço, durante prazos relativamente curtos (períodos não superiores a uma semana), evitando-se problemas decorrentes da absorção de umidade;

- Manutenção preventiva nos transformadores, visando eliminar paralisações de emergência. Constitui basicamente dos seguintes itens: detecção de vazamentos, ensaio de rigidez dielétrica do óleo, inspeção das partes metálicas, teste de isolação e limpeza geral.

i) Manutenção nos sistemas de ar condicionado e ventilação. Efetuar boa manutenção de modo a manter o sistema em perfeitas condições operacionais, evitando a sujeira e o excesso de atrito nas partes rotativas. Para isso, devem-se limpar e lubrificar com frequência mancais e rolamentos visando minimizar o atrito, reduzir ruído e evitar perdas de energia. Procurar limpar as pás dos ventiladores e suas grades de proteção, evitando acúmulo de poeira, que dificulta a passagem de ar;

j) Projeto e construção de planta industrial. Projeto arquitetônico, a ventilação e a iluminação naturais deverão ser aproveitados intensamente, de modo a minimizar o dispêndio de energia nessas aplicações. No projeto elétrico, devem-se escolher com cuidado o nível de tensão de alimentação das máquinas e equipamentos, a localização dos transformadores próximos aos centros de carga, o dimensionamento dos condutores, observando as recomendações da norma brasileira, etc., de modo a minimizar as perdas na distribuição de energia elétrica. A escolha das máquinas e dos equipamentos deve levar em conta a eficiência energética, dando preferência aos modelos que apresentam menores perdas ou menor consumo específico para realizar a mesma tarefa;

k) Circuitos de distribuição. Para a instalação, calcular a seção ótima e mais econômica dos condutores, considerando-se os diversos parâmetros, como o custo do capital e o preço da energia (consultar NBR 5410 - Instalações Elétricas de Baixa Tensão). Utilizar condutores mal dimensionados equivale a efetuar desperdícios consideráveis de energia, além de comprometer a segurança da instalação. Verificar a existência de um ou mais equipamentos de elevada potência e alimentá-los diretamente com alta tensão. Esta prática pode não só reduzir os custos da instalação elétrica, como também evitar desperdícios desnecessários de energia elétrica. A utilização da tensão de $350 \mathrm{~V}$ é, na prática, suficiente para a alimentação da maior parte dos equipamentos da organização;

I) Sistema de demanda das necessidades de fornecimento. Ajuste de Fator de Potência: nos sistemas tarifários convencionais e horosazonal, o ajuste é cobrado quando o fator de potência da unidade consumidora no período de faturamento resulta inferior a 0,92. No caso da Tarifa Azul, o fator de potência é calculado separadamente para os dois segmentos, ponta e fora de ponta;

m) Promover a adoção de formas renováveis de energia, podendo ser compradas, armazenadas, processadas, utilizadas em equipamentos ou em um processo, ou recuperadas.

\section{Projeto e desenvolvimento do inventário de GEE}

As fontes de emissão estão apresentadas na Tabela 5. A organização em estudo possui os seguintes tipos de emissões:

Escopo 1 - emissões diretas:

- Combustão estacionária (processamento de motores)

- Combustão móvel (transporte local)

Escopo 2 - emissões indiretas:

- Combustão estacionára (consumo de eletricidade adquirida)

Escopo 3 - outras emissões indiretas:

- Combustão móvel (deslocações e viagens de negócios de colaboradores)

- Fuga de emissões $\left(\mathrm{CH}_{4}\right.$ e $\mathrm{CO}_{2}$ do desperdício de aterros)

- Combustão estacionária (processamento de combustíveis) 
Tabela 5. Fontes de emissão por escopo

\begin{tabular}{|c|c|c|}
\hline $\begin{array}{l}\text { Escopo Protocolo GHG } \\
\text { (2011) }\end{array}$ & Categorias de Emissão & $\begin{array}{c}\text { Fontes de Emissão - processo } \\
\text { operacional }\end{array}$ \\
\hline 1 - Emissão direta & $\begin{array}{c}\text { Combustão estacionária } \\
\text { (processamento de motores) }\end{array}$ & $\begin{array}{c}\text { Movimentação de materiais } \\
\text { Corte } \\
\text { Calandragem } \\
\text { Soldagem } \\
\text { Jateamento } \\
\text { Pintura } \\
\end{array}$ \\
\hline 1 - Emissão direta & Combustão móvel (transporte local) & $\begin{array}{l}\text { Recebimento de materiais } \\
\text { Corte }\end{array}$ \\
\hline 2 - Emissão indireta & $\begin{array}{c}\text { Combustão estacionária (consumo de } \\
\text { eletricidade adquirida) }\end{array}$ & $\begin{array}{c}\text { Movimentação de materiais } \\
\text { Corte } \\
\text { Calandragem } \\
\text { Soldagem } \\
\text { Jateamento } \\
\text { Pintura } \\
\end{array}$ \\
\hline 3 - Outras emissões indiretas & $\begin{array}{l}\text { Combustão móvel (deslocações e } \\
\text { viagens de negócios de colaboradores) }\end{array}$ & Administrativo \\
\hline 3 - Outras emissões indiretas & $\begin{array}{c}\text { Fuga de emissões ( } \mathrm{CH} 4 \text { e } \mathrm{CO} \text { do } \\
\text { desperdício de aterros) }\end{array}$ & Descarte de resíduos sólidos \\
\hline 3 - Outras emissões indiretas & $\begin{array}{l}\text { Combustão estacionária } \\
\text { (processamento de combustíveis) }\end{array}$ & $\begin{array}{l}\text { Soldagem } \\
\text { Jateamento }\end{array}$ \\
\hline
\end{tabular}

Primeiramente, serão apresentados os cálculos das emissões diretas decorrentes da combustão estacionária dos escopos 1 (processamento de motores) e escopo 3 (processamento de combustíveis). A Tabela 6 traz os dados referentes ao consumo dos combustíveis: óleo diesel, acetileno (outros produtos do petróleo) e gás liquefeito de petróleo (GLP).

Tabela 6. Emissão da combustão de fontes estacionárias - processamento de motores e combustíveis

\begin{tabular}{cccccccccc}
\hline \multirow{2}{*}{ Categoria } & \multicolumn{2}{c}{ Consumo } & \multicolumn{4}{c}{$\begin{array}{c}\text { Fator de emissão } \\
\text { - setor manufatura (kg/un) }\end{array}$} \\
\cline { 3 - 10 } & & & $\mathrm{CO}_{2}$ & $\mathrm{CH}_{4}$ & $\mathrm{~N}_{2} \mathrm{O}$ & $\mathrm{CO}_{2}(\mathrm{~kg})$ & $\mathrm{CH}_{4}(\mathrm{~kg})$ & $\mathrm{N}_{2} \mathrm{O}(\mathrm{kg})$ & $\mathrm{CO}_{2} \mathrm{eq}(\mathrm{t})$ \\
\hline \multirow{2}{*}{ Motor } & Óleo diesel & $1.800 \mathrm{~L}$ & 2,63 & 0,00011 & 0,00002 & 4.734 & 0,20 & 0,04 & 4,75 \\
\multirow{2}{*}{ Combustível } & Acetileno & $5,4 \mathrm{t}$ & $3.130,30$ & 0,12812 & 0,02562 & $16.903,62$ & 0,69 & 0,14 & 16,96 \\
& $\mathrm{GLP}$ & $2.500 \mathrm{~m}^{3}$ & $1.612,86$ & 0,02556 & 0,00256 & 4.032 .150 & 63,90 & 6,40 & $4.035,48$ \\
\hline
\end{tabular}

Fonte: IPCC (2006).

Para o cálculo das emissões decorrentes do escopo 1 - combustão móvel (transporte local) identificou-se a distância média percorrida durante o ano-base dos dois tipos de veículos utilizados no transporte interno de cargas que são empilhadeiras e trator, e o consumo de combustível total. A partir disso, calculou-se as emissões em tCO $\mathrm{tCe}_{\text {2eq. }}$ Os resultados estão apresentados na Tabela 7.

Tabela 7. Emissão do transporte interno de cargas

\begin{tabular}{|c|c|c|c|c|c|c|c|c|}
\hline $\begin{array}{c}\text { Fonte } \\
\text { Emissora }\end{array}$ & $\begin{array}{c}\text { Tipo } \\
\text { Combustível }\end{array}$ & $\begin{array}{l}\text { Distância } \\
\text { Total }(\mathbf{k m})\end{array}$ & $\underset{(\mathrm{km} / \mathrm{L})}{\text { Consumo }}$ & $\begin{array}{c}\text { Quantidade } \\
\text { consumida } \\
\left(\mathrm{m}^{3}\right)\end{array}$ & $\mathrm{PCl}$ & $\begin{array}{l}\text { Energia } \\
\text { (GJ) }\end{array}$ & $\begin{array}{c}\text { Fator de } \\
\text { emissão } \\
\left(\mathrm{kgCO}_{2} / \mathrm{GJ}\right)\end{array}$ & $\begin{array}{c}\text { Emissão } \\
\text { (tCO } 2 \text { eq) }\end{array}$ \\
\hline r. & & 2.220 & 2 & 0,89 & 35,5 & & 74,1 & 2,36 \\
\hline Trator & Diesel & 1.110 & 2,47 & 0,45 & 35,5 & 15,95 & 74,1 & 1,18 \\
\hline
\end{tabular}

Ainda dentro da categoria combustão móvel, porém agora fazendo parte do escopo 3, estão outras emissões provenientes das deslocações e viagens de negócios de colaboradores, conforme Tabela 8. Foi aplicado um questionário aos 33 colaboradores da empresa, porém houve apenas o retorno de 15. Neste questionário, havia perguntas sobre o veículo de transporte utilizado para ida e volta do trabalho, combustível utilizado e distância percorrida. As mesmas perguntas foram feitas para as viagens de negócios, quando aplicável aos colaboradores. 
Tabela 8. Emissão do transporte de colaboradores

\begin{tabular}{|c|c|c|c|c|c|c|c|}
\hline $\begin{array}{c}\text { Tipo } \\
\text { Combustível }\end{array}$ & $\begin{array}{l}\text { Distância } \\
\text { Total (km) }\end{array}$ & $\begin{array}{c}\text { Consumo } \\
(\mathrm{km} / \mathrm{L})\end{array}$ & $\begin{array}{c}\text { Quantidade } \\
\text { Consumida } \\
\text { (L) }\end{array}$ & $\begin{array}{c}\mathrm{PCl} \\
\left(\mathrm{GJ} / \mathrm{m}^{3}\right)\end{array}$ & $\begin{array}{c}\text { Energia } \\
\text { (GJ) }\end{array}$ & $\begin{array}{c}\text { Fator de } \\
\text { Emissão } \\
\left(\mathrm{kgCO}_{2} / \mathrm{GJ}\right)\end{array}$ & $\begin{array}{c}\text { Emissões } \\
\text { (tCO} 2 \mathrm{eq})\end{array}$ \\
\hline Álcool (km) & 4662 & 7,88 & 591,62 & 21,3 & 12,60 & 70,8 & 0,89 \\
\hline Gasolina (km) & 42180 & 11,50 & $3.667,83$ & 29,5 & 108,20 & 69,3 & 7,501 \\
\hline Diesel (km) & 47730 & 2,47 & $19.323,89$ & 35,5 & 685,99 & 74,1 & 50,83 \\
\hline
\end{tabular}

A partir desses dados, calculou-se a distância média percorrida durante o ano-base de cada colaborador. Porém, outra variável teria que ser utilizada para o cálculo das emissões que era o consumo de combustível pelos veículos. Utilizou-se como fontes a Tabela de Consumo/ Eficiência Energética de Veículos Automotores Leves do Programa Brasileiro de Etiquetagem do INMETRO (2012) e os resultados obtidos em Oliveira e Filho (2009).

As únicas emissões pertencentes ao escopo 2 identificadas neste inventário são as provenientes do consumo de eletricidade adquirida, a qual representa a maior quantidade de emissões de GEE, como pode ser visualizado na Tabela 9.

Tabela 9. Emissão da combustão de fonte estacionária - consumo de eletricidade adquirida

\begin{tabular}{cccccc}
\hline $\begin{array}{c}\text { Protocolo GHG } \\
\text { (2011) }\end{array}$ & Categorias de Emissão & $\begin{array}{c}\text { Emissão } \\
\text { (ano-base) }\end{array}$ & Unidade & $\begin{array}{c}\text { Fator de } \\
\text { emissão }\end{array}$ & $\begin{array}{c}\text { Cálculo das } \\
\text { emissões }\end{array}$ \\
\hline $\begin{array}{c}\text { Emissão } \\
\text { indireta }\end{array}$ & $\begin{array}{c}\text { Combustão estacionária } \\
\text { (consumo de eletricidade } \\
\text { adquirida) }\end{array}$ & $1.738,88$ & MWh & 0,0293 & 50,95 \\
\hline
\end{tabular}

Fonte: MCT (2007).

Por fim, dentro do escopo (âmbito) 3, calculou-se ainda outras emissões indiretas provenientes de fuga de emissões $\left(\mathrm{CH}_{4}\right.$ e $\left.\mathrm{CO}\right)$ da disposição final dos resíduos sólidos decorrentes das operações da organização inventariante no ano-base. Os resíduos sólidos gerados na organização são destinados para dois aterros industriais controlados, os quais estão localizados em áreas com características similares e, portanto, os dados para cálculo das emissões de GEE foram agregados, conforme recomendação da metodologia escolhida.

A precipitação anual média dos locais de disposição de resíduo atinge mais de $1.000 \mathrm{~mm} / \mathrm{ano}$ e a temperatura anual média é menor de $20^{\circ} \mathrm{C}$. A quantidade de resíduos aterrada foi de $28,86 \mathrm{t} / \mathrm{ano}$. Fazem parte da composição do resíduo: $20 \%$ papel/ papelão, $5 \%$ resíduos alimentares, $10 \%$ madeira, $3 \%$ resíduos de jardim e parque e $62 \%$ materiais inertes.

Os aterros utilizados para a deposição dos resíduos possuem controle do aterramento de resíduo, não recuperam biogás e incluem todas as seguintes estruturas para introduzir ar nas camadas de resíduos: (i) material de cobertura permeável; (ii) sistema de drenagem de chorume; (iii) tanque de regulação; e (iv) sistema de ventilação de gases. Portanto, a classe da qualidade destes aterros é E aterro semi-aeróbio manejado resultando num fator de correção de metano (MCF) igual a 0,5 e num fator de oxidação igual a 0,0. Foi adotado o default do IPCC (2006), que é igual a 0,5 devido não se conhecer a fração de $\mathrm{CH}_{4}$ no biogás.

As emissões totais de resíduos sólidos aterrados no ano-base totalizam $0,057 \mathrm{tCH} /$ ano e 1,187 $\mathrm{tCO}_{2 \text { eq. }}$ Na Tabela 10 estão documentadas as quantidades de emissões de GEE de cada escopo em $\mathrm{tCO}_{2 \text { eq. }}$

Tabela 10. Quantificação de emissões de GEE resultante do inventário de emissões

\begin{tabular}{|c|c|c|}
\hline Protocolo GHG (2011) & Categoria de emissão & $\begin{array}{c}\text { Cálculo das } \\
\left.\text { emissões (tCO }{ }_{2 \mathrm{eq}}\right)\end{array}$ \\
\hline 1 - Emissão direta & Combustão estacionária (processamento de motores) & 4,75 \\
\hline \multirow{3}{*}{$\begin{array}{l}1 \text { - Emissão direta } \\
2 \text { - Emissão indireta } \\
3 \text { - Outras emissões } \\
\text { indiretas }\end{array}$} & Combustão móvel (transporte local) & 1,18 \\
\hline & Combustão estacionária (consumo de eletricidade adquirida) & 50,95 \\
\hline & Combustão móvel (deslocações e viagens de colaboradores) & 59,22 \\
\hline \multirow{3}{*}{$\begin{array}{c}3 \text { - Outras emissões } \\
\text { indiretas } \\
3 \text { - Outras emissões } \\
\text { indiretas }\end{array}$} & Fuga de emissões ( $\mathrm{CH} 4$ e $\mathrm{CO}$ do desperdício de aterros) & 1,18 \\
\hline & Combustão estacionária (processamento de combustíveis) & $4.052,44$ \\
\hline & TOTAL & $4.169,73$ \\
\hline
\end{tabular}


As ações dirigidas consideradas viáveis tecnicamente para serem implementadas pela organização incluem os seguintes tipos de iniciativas:

- Gerenciamento do uso e demanda de energia;

- Eficiência energética;

- Melhoria do processo e tecnologia;

- Gerenciamento de demandas de transporte e viagens;

- Substituição de combustível.

Nota-se que todas as ações acima foram também definidas como oportunidades de melhoria para o sistema de gestão de energia da organização, conforme abordado com mais profundidade no item 3.2.5.

\section{CONCLUSÕES}

Conclui-se que para se estabelecer um sistema de gestão de energia é imprescindível que se tenham ferramentas adequadas para o levantamento de dados e informações, as quais irão compor a revisão energética e a definição da linha de base. Uma revisão energética elaborada com profundidade permite a obtenção de um diagnóstico do desempenho energético da organização mais preciso e, com isso, os ganhos com as melhorias tendem a ser mais representativos. Foi possível verificar que o sistema de gestão de energia da organização em estudo apresenta diversas fraquezas o que pode estar ocasionando perdas de energia, perda de produtividade, gastos com consumos desnecessários de energia, aumento das emissões de gases de efeito estufa, entre outros.

É evidente que a adoção completa da norma ISO 50001 irá trazer grandes mudanças na organização estudada, principalmente no que se referem à adequação dos controles, procedimentos operacionais e aspectos culturais. No entanto, estas mudanças certamente trarão os benefícios propostos pela norma que são: melhorar o uso dos seus atuais consumos de energia; criar transparência e facilitar a comunicação sobre a gestão dos recursos energéticos; promover práticas de melhor gerenciamento de energia e reforçar os comportamentos para uma boa gestão de energia; implementar novas tecnologias energeticamente eficientes; promover a eficiência energética em toda a cadeia de abastecimento; permitir a integração com outros sistemas de gestão organizacionais, tais como qualidade, meio ambiente, saúde e segurança; conduzir todas essas melhorias do sistema de gestão de energia para a redução das emissões dos gases de efeito estufa. Isto se deve ao fato de que empresas já relatam uma significativa redução de consumo de energia após a implantação da norma ISO 50001.

Também foi possível concluir que a elaboração de inventários de GEE de acordo com os requisitos estabelecidos pela ISO 14064 serve para monitorar o desempenho do sistema de gestão de energia devido ao fato de as oportunidades de melhoria do SGE serem similares às atividades para redução dos GEE. Diante deste panorama, conclui-se que o meio ambiente será o maior beneficiado, pois melhorias no desempenho energético das organizações referem-se ao uso racional e à conservação de energia. Portanto, são válidos todo e qualquer esforço adotado em prol deste tema, mesmo que neste momento ainda pareçam complexos e desafiadores.

\section{REFERÊNCIAS}

ABNT - Associação Brasileira de Normas Técnicas. ABNT NBR ISO 50001. 2011. 24 p.

ABNT - Associação Brasileira de Normas Técnicas. Cartilha ISO 50001:2011. 2012. 16 p.

ANBT - Associação Brasileira de Normas Técnicas. ABNT NBR ISO 14064-1. Gases de efeito estufa. Parte 1: Especificação e orientação a organizações para quantificação e elaboração de relatórios de emissões e remoções de gases de efeito estufa. 2007. 28 p.

ANEEL - Agência Nacional de Energia Elétrica. Atlas de Energia Elétrica do Brasil. Brasília, 3. ed. 2008. 236 p.

COPEL - Companhia Paranaense de Energia. Manual de Eficiência Energética na Indústria. Curitiba, 2005. 155 p. 
IEA - International Energy Agency. Key World Energy Statistics 2012. 2012. 80 p.

IEA - International Energy Agency. World Energy Outlook. 2008. 578 p.

INMETRO - Instituto Nacional de Metrologia, Qualidade e Tecnologia. Programa Brasileiro de Etiquetagem - PBE. 2012. Disponível em: <http://www2.inmetro.gov.br/pbe> Acesso em: 02/09/2013.

IPCC - Intergovernmental Panel on Climate Change. Guidelines for National Greenhouse Gas Inventories. National Greenhouse Gas Inventories Programme. 2006. Disponível em: <http://www.ipcc-nggip.iges.or.jp/public/2006gl/vol4.html> Acesso em: 02/09/2013.

KUSTERKO, S. K. Uso de Indicadores de Desempenho como Auxílio nos Estudos de Eficiência Energética em Sistemas de Abastecimento de Água. 2009. 92 p. Monografia (Graduação em Engenharia Sanitária e Ambiental), Universidade Federal de Santa Catarina, Florianópolis.

OLIVEIRA, G.; FILHO, R. D. O. Análise do consumo de combustível de ônibus urbano. In: XVIII Congresso de Pesquisa e Ensino em Transportes. Florianópolis, p. 1479-1491, 2009.

PROTOCOLO GHG. Normas corporativas de transparência e contabilização do protocolo de gases de efeito estufa. World Business Council for Sustainable Development e World Resources Institute, Greenhouse Gas Protocol Initiative. Edição revisada, 2011. 114 p.

REIS, S. G.; JÚNIOR, I. J. N.; MORGAN, B. F. Definição de metas para avaliação de desempenho de agências bancárias. In: XIII Congresso de Controladoria e Contabilidade. São Paulo, 2002. 16 p.

SEBRAE - Serviço Brasileiro de Apoio às Micro e Pequenas Empresas. Anexo VII - Metas quantitativas e qualitativas para as incubadoras de empresas modalidades Tipo 1. Brasília, 2011. 12 p. Disponível em: <http://www.sebrae.com.br/customizado/sebrae/institucional/chamadas-deprojetos/inovacao-e-tecnologia> Acesso em: 02/09/2013. 